\title{
DERECHO PENAL DE ENEMIGO VS DERECHO PENAL DEL CIUDADANO. EL DERECHO PENAL DE EMERGENCIA EN COLOMBIA: ENTRE LA PAZ Y LA GUERRA
}

\author{
Alejandro David Aponte \\ Profesor Asociado de Derecho Penal y Teoría del Derecho \\ Facultad de Derecho \\ Universidad de los Andes \\ Bogotá
}

\section{INTRODUCCIÓN}

El presente trabajo, como estudio y crítica al eficientismo penal, es una reflexión acerca del derecho penal de la emergencia en Colombia. Éste, ligado a la lógica permanente de los estados de excepción, funciona en el país desde hace más de cinco décadas. En Colombia, desde hace cincuenta años, no existe un solo gobernante que haya podido gobernar sin recurrir a la figura del estado de sitio o del estado de excepción.

El análisis del derecho penal de la emergencia, como quiera que se trata de un síntoma de la crisis que padece el derecho penal moderno desde sus orígenes y que hoy en día se encuentra articulado a numerosas legislaciones antiterroristas de occidente, puede aportar elementos de interpretación de realidades diversas que aquejan a naciones de este continente. Razón por la cual, el estudio de la emergencia penal puede ser de interés para el público chileno, no sólo como ilustración del caso particular colombiano, sino en función de modelos que hoy tienden a expandirse desmesuradamente como correlato de una especie de derecho penal de la postmodernidad, paradógicamente premoderno. Ningún país del mundo occidental escapa a la expansión incontrolada del derecho penal, que encuentran en el derecho penal de la excepción un impulso decisivo para dicha extensión.

En el caso colombiano, el derecho penal es el que ha sufrido la mayor cantidad de modificaciones introducidas por las declaratorias de excepción. En la década de los años 60 y 70, como expresión además de hechos que eran notorios en todo el continente latinoamericano, como es el hecho de la promoción, desde los E.E.U.U, de la "Doctrina de la Seguridad Nacional", la noción que estructuraba el derecho penal de la emergencia, era la noción de "seguridad". Se trataba de la incorporación de modelos totalitarios de política criminal y de modelos de corte autoritario de derecho penal a partir, entre otras cosas, de una lectura radical del texto de Carl Schmitt sobre el 
concepto de lo político. ${ }^{1}$ La irreductibilidad de la concepción de lo político en Schmitt, según la cual la política sólo puede concebirse como la confrontación inevitable entre enemigos, servía como base para identificar el enemigo central: el comunismo internacional. La noción de "seguridad" se leía a partir de este código político de la enemistad.

Una de las consecuencias más concretas de la implementación de un derecho penal basado en una lectura radical de la noción de seguridad, fue la criminalización y persecución indiscriminada de todo tipo de actores que se movían en ese entonces en lógicas de acción política distintas de la actuación guerrillera que era el paradigma de la violencia política. El guerrillero constituía el gran enemigo. A su lado, se criminalizaron otros actores, como ciertos sectores de la opinión pública, miembros de partidos políticos de izquierda, estudiantes, campesinos, obreros y otros actores que fueron perseguidos a través del derecho penal. En una gran parte de países de América Latina, la persecución se llevó a cabo de una manera radical desde las dictaduras militares. En el caso colombiano, el problema ha sido más complejo. En este país no han existido dictaduras militares. Por esa razón, el derecho penal de la emergencia ha actuado históricamente desde la ambivalencia que genera la permanencia de un sistema democrático muy consolidado, pero que ha vivido siempre en emergencia. El derecho penal, que articulado a formas radicales de búsqueda de la seguridad, y que puede llamarse desde entonces como derecho penal de enemigo actuaba, en esa época, a través de los consejos verbales de Guerra. Es decir, a través de la justicia penal militar aplicada a los civiles.

En razón a lo anteriormente expuesto, todo el derecho publico en este país está condicionado por las relaciones ambivalentes y complejas entre guerra y derecho. Se trata de la democracia más antigua del continente $y$, sin embargo, a lo largo del siglo XIX, después de la guerra de independencia frente a España, el pais vivió numerosas guerras7 civiles. En el siglo XX, la violencia política, sobre todo en las últimas cinco décadas, ha alcanzado niveles extremos. Colombia pasa el umbral del siglo XX al siglo $X X I$, soportando un conflicto armado interno, crónico y degradado, en el cual los civiles son los que constituyen la mayor parte de sus víctimas. Éste es el contexto general en el cual se debe estudiar la dinámica del derecho penal de emergencia. Además, se trata de un contexto que determina de alguna manera el derecho penal ordinario y todo el sistema del derecho público en Colombia.

${ }^{1}$ SCHMITT Carl, Der Begriff des Politischen. Text von 1932 mit einem Vorwort und drei Corollarien, Berlin, 1991. 


\section{Sobre una noción particular de "eficiencia" en el derecho penal}

La noción de seguridad, propia de las décadas de los 60 y 70 , sufre una transformación esencial desde la década de los años 80: de la idea de seguridad se pasa a la idea de "eficacia" o de "eficiencia" en el derecho penal. La crisis de la administración de justicia se concibe ante todo como "crisis de eficiencia" de la misma.

Teniendo en cuenta el nuevo paradigma de interpretación de la crisis del sistema de justicia penal, una comisión del gobierno colombiano, a finales de la década de 1980 , viajó a países europeos, especialmente a Italia, a España y a Alemania, a observar cómo se desarrollaba en esos países la lucha contra el terrorismo. Como resultado de ello, se elaboró un sistema de justicia especial de emergencia, que se concretó en el denominado "Estatuto para la defensa de la Justicia". (Decreto de estado de sitio No. 2790 de 1990, complementado por el decreto, también de estado de sitio, № 0099 de 1991).

La expedición del Estatuto, un verdadero código de procedimiento penal de emergencia, con más de 100 artículos y paralelo al código de procedimiento penal ordinario, se remite a una circunstancia específica de la violencia en Colombia: en la década de los 80 s, ocurrió un hecho central que le dio una dinámica especialmente dramática a la violencia política y fue la consolidación de las mafias del narcotráfico. Al final de la década, especialmente entre los años 1989 y 1999, el narcotráfico, perseguido de manera radical por el Estado y bajo la amenaza de que sus miembros pudieran ser extraditados a los E:E.U.U y ser allí castigados, le declaró la guerra al Estado colombiano. Fue la época del narcoterrorismo urbano. Muchos narcotraficantes, convertidos en terroristas, colocaron un énfasis especial dentro de su acción a la persecución indiscriminada de funcionarios de la administración de justicia. Numerosos funcionarios de la administración de justicia fueron amenazados o muertos, especialmente jueces, incluso magistrados de la Corte Suprema de Justicia. También, al mismo tiempo, policías y toda clase de funcionarios, además de una gran cantidad de civiles que fueron sacrificados en las calles como víctimas inocentes.

Contra estos actores -agresivos terroristas- se elaboró en principio dicho Estatuto especial. El centro de su normatividad fue la reserva de identidad de todos los funcionarios dentro del proceso penal. En 1991 se creó la Fiscalía general de la Nación. de manera que en el proceso penal, los fiscales, los jueces y los testigos, pasaron a ser secretos. En ningún caso los sindicados o procesados podían conocer los funcionarios que los juzgaban. Se trató por eso de la denominada "justicia sin rostro" o "justicia secreta".

La nueva versión de "eficiencia" que alimentó el Estatuto desde el primer momento, fue clara: la eficiencia y la eficacia del sistema penal se comenzaron a entender, y hoy en día es un paradigma generalizado, como la producción a toda costa 
de sentencias condenatorias. Es decir, la eficacia ha sido concebida, especialmente por el Ejecutivo y luego de manera generalizada en otros ámbitos institucionales como en sectores de la Fiscalía y en algunos despachos de la Sala Penal de la Corte Suprema de Justicia y de la Corte Constitucional, como sinónimo de condena.

La eficacia ha obrado como fin absoluto, sin atención real a los medios utilizados para su logro. Se presenta un número abstracto de resultados -las sentencias condenatorias- que mostrarían la supuesta "eficacia" del sistema judicial, sin tener en cuenta en ningún caso la manera cómo se ha llegado a ese número de sentencias. Es decir, se da a conocer un resultado final, abstracto, eludiendo la realidad de negación cotidiana de derechos y garantías por parte de la justicia penal de emergencia. En todos los años de vigencia de la justicia sin rostro, ha sido sintomático el uso abstracto de estadísticas que terminan produciendo un efecto social apenas simbólico, pues el ciudadano común no observa ningún cambio real en la dinámica cotidiana de la violencia que lo amenaza. Un ejemplo de este uso instrumental del supuesto logro de la eficacia, importante además, porque se dio en un momento en el cual la justicia sin rostro apenas comenzaba a regir, es la afirmación del ministro de justicia del año de 1991, según la cual los jueces sin rostro constituían a su juicio un recurso eficaz, "pues desde el 16 de enero, hasta el mes de julio, se han producido 230 sentencias : 187 condenatorias y apenas 43 absolutorias". ${ }^{2}$ En virtud incluso de este nuevo paradigma de la eficacia, cuando el sistema penal produce una sentencia absolutoria, se dice que se trata de impunidad. Es decir, si un fiscal no encuentra méritos para proseguir la investigación o si un juez declara una persona inocente, entonces se dice que no funciona el sistema penal, que se ha producido una situación de ineficacia, es decir, de impunidad.

Así entonces, de manera general se puede decir que el eficientismo penal es un modelo de derecho penal de la emergencia, edificado sobre una noción particular de la eficiencia, a partir de la cual se privilegia dicha noción de eficiencia sobre los derechos fundamentales y las garantías legales y constitucionales. Se trata de un modelo de derecho penal que se estructura a partir de una lógica de fines en la cual prevalece la mera razón instrumental sobre la razón valorativa. Como lo señala Baratta, "el eficientismo penal es una nueva forma del derecho penal de la emergencia, que es la enfermedad crónica que siempre ha acompañado la vida del derecho penal moderno". ${ }^{3}$

\footnotetext{
2 Jaime Giraldo Ángel, "El Espectador", 3 de julio de 1991.

${ }^{3}$ BARATTA Alessandro, "Política criminal. Entre la política de seguridad y la política social en países con grandes conflictos sociales y políticos", en: "Ciencias Jurídicas. Seminarios" 9, Bogotá, (1998), p.63.
} 


\section{Justicia penal de emergencia y derecho penal político}

Como se ha dicho, el eficientismo penal constituye un nuevo modelo de derecho penal de la emergencia. Se trata, sobre todo, de un modelo con marcada vocación instrumental, que agencia en su dinámica práctica una justicia penal igualmente instrumental. La administración de justicia adquiere ese carácter, en tanto tiende a servir a intereses particulares situados en el ámbito de las decisiones políticas coyunturales, pragmáticas o meramente partidistas; o en tanto pretende dar respuesta a exigencias que se originan en otros ámbitos, como es el caso por ejemplo de aquellas exigencias que surgen del conflicto armado interno crónico que vive Colombia. El derecho penal, fruto del eficientismo, constituye por ello un derecho penal altamente politizado. Se trata de un derecho penal político.

Con esta categoría, no se hace referencia desde luego a un sistema de derecho penal influido o relacionado con la política: ello le es en todo caso inherente. La noción misma de política criminal por ejemplo, refleja y expresa dicha relación. De otra parte, como derecho público, el derecho penal, como es el caso del derecho constitucional, lleva en su seno la idea misma de lo político. De lo que se trata en este caso es, al contrario, de una verdadera apropiación del derecho penal por parte de la política: de una instrumentalización del derecho penal para fines exclusivamente políticos. Esta noción la aclara un autor que se ocupa del tema en el caso alemán por ejemplo: "Uno puede retomar una afirmación en relación con el derecho penal. Para citar un caso : se puede afirmar que el derecho penal, tal como el derecho constitucional, es por naturaleza político; o se puede afirmar también que la política se apodera del derecho penal como mero instrumento para lograr sus fines (es a esa última afirmación que se hace referencia: el 'derecho penal político' es concebido en su carácter y función meramente instrumental)". ${ }^{4}$ Tal como lo hace este autor, es al carácter puramente instrumental del derecho penal, al cual se alude aqui cuando se hace referencia a un derecho penal político. Interesante es observar además cómo el derecho penal se convierte paulatinamente en un instrumento de la política meramente partidista: "El derecho penal ha dejado de ser un medio limitado y un instrumento para asegurar la libertad, y ha pasado a ser un medio absoluto autorizado para la consecución de cualquier tipo de finalidad política. El derecho penal se ha convertido hoy en un instrumento de la política partidista. Lastimosamente, este cambio fundamental en la filosofía del derecho penal, no se discute hoy suficientemente en el ámbito de la ciencia del derecho". 5

\footnotetext{
${ }^{4}$ VORMBAUM Thomas, "Politisches Strafrecht", en: ZStW 107 (1995), p. 734.

${ }^{5}$ Ibidem, p. 734. Esta tendencia hacia un derecho penal político, es además recalcada por diversos autores. PeterAlexis Albrecht, en un trabajo en el cual concibe que el derecho penal transita el camino desde el Estado de derecho liberal hacia el Estado-social intervencionista, afirma que "EI bien conocido derecho penal político constituye una afirmación con amplia repercusión actual y a la vez prototípica. Nos movemos aqui en la médula
} 
En el caso colombiano, además de darse el fenómeno de un derecho penal político-instrumental, se trata en general de una forma muy especial de la acción política: de la política concebida y vivida fundamentalmente como confrontación irreductible entre enemigos.

De esta forma, la justicia penal eficientista se expresa a través de un derecho penal que no es concebido y utilizado en la práctica como ultima ratio sino, al contrario, como prima ratio: que tiende a ser movilizado con el propósito de resolver todo tipo de problemas económicos, sociales o políticos. Es un modelo que tiende, al mismo tiempo, a ser totalizante, respecto no sólo del sistema derecho penal, sino del sistema del derecho en general.

\section{De la justicia penal de emergencia en el marco general de las relaciones entre guerra y derecho en Colombia}

Para situar correctamente los alcances de la justicia penal de emergencia, es necesario ubicarla en el contexto más genérico de las relaciones entre guerra y derecho: es la dinámica de dicha relación, aquella que en mayor medida le otorga contenido específico al derecho penal eficientista en el caso colombiano.

Las relaciones entre guerra y derecho encuentran a su vez un punto de referencia más genérico en la confusión histórica tradicional que en el país ha existido entre la guerra y la política. Desde la proliferación de guerras civiles en el siglo XIX, se ha manifestado dicha confusión. Si es dable, con autores como Clausewitz, concebir la guerra como la continuación de la política por otros medios, en el caso colombiano, la ecuación sufre igualmente en nuestra historia una variación fundamental: en muchas ocasiones constituye la política en cambio, la continuación de la guerra por otros medios. Es decir, la guerra tiende a convertirse en un fin en sí misma, de manera que la política es convertida en un medio para hacer la guerra: para servir a ella como fin. Como consecuencia de ello es que de una manera reiterada, a problemas de carácter político, se les otorga en la práctica un tratamiento militar o meramente punitivo.

La militarización o criminalización de fenómenos políticos y sociales, revela además las paradojas múltiples que atraviesan la historia de Colombia y que le otorgan especificidad incluso en el contexto latinoamericano. Guerra y derecho, guerra y

del Estado-social intervencionista". ALBRECHT Peter-Alexis, "Das Strafrecht auf dem Weg vom liberalen Rechtsstaat zum sozialen Interventionsstaat", en: KritV, (1988), p. 200 y S. Por su parte, Hassemer recalca que el "derecho penal está situado, tanto en la teoría como en la praxis, en el camino hacia la tecnología social. Él se reduce hoy a ser un mero instrumento de la politica interior (en la economía, en la ecología, en la salud, en las finanzas, en la seguridad)". HASSEMER Winfried, "Sozialtechnologie und Moral ; Symbole und Rechtsgüter", en: Heike Jung, Heinz-Müller Dietz, Ulfrid NEUMANN (editores), Recht und Moral, Baden-Baden, 1995, p. 329. 
política, son expresiones de dilemas más genéricos, como es el caso de la coexistencia entre la violencia y la democracia, o entre la legitimidad y la violencia. Al lado de las instituciones estatales, de un funcionamiento pautado y reglado de las mismas, permanece una realidad, no sólo caótica, sino completamente desinstitucionalizada. Se trata de una realidad tan radical que hace ver las instituciones casi como meramente accidentales -contingentes- $y$, en todo caso, extrañas a grandes segmentos de la población colombiana.

\section{La lógica de la excepción: consolidación de una cultura de la emergencia}

Ahora bien, no es posible entender la existencia de un orden jurídico, social y político, que posee una institucionalización democrática formal, que tiene una Constitución Política y una regulación normativa estricta de todo el funcionamiento estatal, pero que al mismo tiempo sobrevive en un contexto históricamente marcado por la violencia política y social, sin comprender bien el fenómeno jurídico y político de la excepción. Es en la excepción y no en la normalidad, que ha vivido Colombia, al mismo tiempo que es el derecho penal el sistema jurídico mayormente condicionado por dicha situación de excepcionalidad. El estado de sitio, tanto en el siglo pasado, como hasta la década del noventa del presente $y$, actualmente -bajo la Constitución Política de 1991- el estado de excepción, se colocan en el centro de la tensión entre guerra y derecho, entre orden y violencia, entre democracia y violencia. Es la apelación sistemática a la figura de la excepción, aquello que ha generado en Colombia una cultura de la emergencia como correlato de la justicia penal de emergencia.

\subsection{Carl Schmitt: del "decisionismo" como una teoría de la soberanía}

El estudio de los mecanismos de excepción, no sólo ayuda a explicar en alguna medida la coexistencia con la violencia por parte de un orden jurídico-político estrictamente regulado, sino que ayuda particularmente a reconocer quién y cómo se ejerce el poder en una sociedad. Ello, más allá de aquella regulación constitucional y legal que para dicho ejercicio se encuentre prevista. Allí reside una de las claves para una comprensión coherente del eficientismo penal: su construcción y lógica de funcionamiento, revelan el marco real en el cual se ejerce el poder, por lo menos el poder que se manifiesta con el uso del derecho penal, en su versión especial como producto sistemático de normas de carácter excepcional. Con este uso se expresan, al mismo tiempo, los cambios que la norma penal genera en todo el orden jurídico, social y político del país. Por esta razón, se hace necesario detenerse, a nuestro juicio, en el estudio del "decisionismo" como una teoría de la soberanía, siendo Carl Schmitt el autor que lo ha desarrollado más a fondo como teoría jurídico-política. 


\subsection{El decisor como el "soberano"}

Si en Colombia existe para la "normalidad", como en todas las democracias occidentales, una separación funcional del poder público, de tal forma que el desarrollo de políticas legislativas penales -la producción de la política criminal- es establecida en principio como una tarea del órgano legislativo, en la realidad de anormalidad que se ha vivido, se ha producido un desplazamiento radical de esa función legislativa: ella se ha concentrado históricamente y se concentra hoy, en el poder Ejecutivo. Éste, liderado por el Presidente de la República, ha sido el encargado por excelencia de producir la política criminal, por lo menos la política criminal de emergencia, que en la realidad constituye la política criminal de más impacto sobre todo el orden social, jurídico y político. ${ }^{6}$ Así, de una manera general, con la frase radical con que Carl Schmitt inicia su Teología Política de 1922, se puede entender el primer gran aspecto clave de la justicia penal de emergencia: "Soberano es quien decide sobre el estado de excepción" ? En el caso colombiano, el soberano, desde el punto de vista de la excepción -que ha pasado a ser la regla- ha sido históricamente el poder ejecutivo.

Al poder ejecutivo lo ha seguido en Colombia, desde la creación en 1991 de la Corte Constitucional, esta Corte en la tarea de hacer la política criminal. La Corte Constitucional se ha convertido en un co-decisor de la política criminal de emergencia. $\mathrm{Ha}$ existido en los últimos años un excesivo protagonismo del juez constitucional que, si bien en una gran mayoría de los casos ha sido favorable a un derecho penal

${ }^{6}$ Ello sigue ocurriendo así, a pesar de los cambios significativos introducidos por el nuevo marco constítucional establecido desde 1991 y que pretenden restringir la producción de normas penales de emergencia por parte del poder Ejecutivo. Por ejemplo, el numeral $3^{\circ}$ del artículo 214 que contiene normas comunes en relación con los estados de excepción, establece que "No se interrumpirá el normal funcionamiento de las ramas del poder público ni de los órganos del Estado". Dicha norma se ha establecido precisamente para evitar que el Ejecutivo, por vía de excepción, elabore códigos de procedimiento penal o de carácter sustantivo, costumbre habitual y que de hecho se halla a la base de la expedición del "Estatuto para la Defensa de la Justicia". De otra parte, el artículo 252, cuya ubicación es muy interesante, porque constituye una limitación al poder Ejecutivo, prevista desde la institución de la Fiscalía General de la Nación, dispone que "Aun durante los estados de excepción de que trata la Constitución en sus artículos 212 y 213 , el gobierno no podrá suprimir ni modificar los organismos ni las funciones básicas de investigación y juzgamiento". Esta norma debe interpretarse en relación con la prohibición fundamental establecida en la parte final del artículo 213: "En ningún caso los civiles podrán ser investigados por la justicia penal militar". En los origenes de estas normas se encuentra el propósito por parte de los constituyentes de evitar que el Ejecutivo, por vía de excepción, creara por ejemplo Consejos verbales de guerra aplicados a civiles. Al mismo tiempo, tienen la pretensión general de limitar al poder Ejecutivo como legislador de excepción. No obstante, tan sólo pocos meses después de haberse expedido la Constitución Política, el Ejecutivo, aludiendo a la grave crisis que a su juicio se produciría con una salida masiva de presos procesados por la justicia sin rostro, en razón a la concesión para ellos del beneficio de la libertad provisional, declaró el estado de conmoción interior. En este caso, desconociendo las normas constitucionales inmediatamente citadas, el presidente de la República, por vía de excepción, impuso a los fiscales y jueces una interpretación determinada de normas penales en conflicto. bajo el argumento insostenible de que la aplicación de una ley y el reconocimiento del derecho a la libertad, pueden causar conmoción social, cuando precisamente el estado de excepción está hecho para casos límites en los cuales se le escape a la ley la regulación de los hechos.

${ }^{7}$ SCHMITT Carl, Politische Theologie. Vier Kapitel zur Lehre von der Souveränität, sexta edición. Berlin, 1993, p. 13. 
democrático, también ha significado un exceso en las funciones que le corresponden a dicho juez, con las implicaciones concretas que ello trae para un ejercicio consistente y democrático del poder político. Se trata de un fenómeno que han vivido otros países, como es el caso de Italia: se trata de un desplazamiento de la pretensión de legitimidad hacia la administración de justicia, que termina creando disfunciones graves en la forma misma en que se imparte la justicia penal.

Ahora bien, el problema principal que se genera con la apelación permanente al mecanismo excepcional, radica en que se ha desgastado este mecanismo. Se ha pervertido completamente el mecanismo de lo excepcional además, en razón a que se crean por vía excepcional figuras que en principio deberían tener un carácter transitorio, pero se les asigna una vigencia de 8 ó 10 años. ¿Cómo es posible que una norma transitoria tenga una vigencia de 8 años? Así ocurrió con la ley 504 de 1999 que fue establecida como una ley de tránsito de la justicia sin rostro, a una justicia normalizada. Sin embargo, el "tránsito" se estableció para 8 años.

Puede agregarse también que la perversión de lo excepcional se encuentra en su utilización desmesurada. Según Carl Schmitt, el caos no da sentido jurídico. Por lo tanto, lo importante es, frente al caso extremo, decidir, no importa cómo, sino hacerlo. Lo único importante es quién se encuentra en ese momento para decidir. Esa dinámica, usada para cualquier tipo de hechos simplemente concebidos como no "normales", ha degradado la noción de lo excepcional en Colombia. Ya no se trata en realidad de casos extremos. $^{8}$

Una norma de emergencia puede haber sido por ejemplo incorporada por fuerza de la decisión al orden jurídico en un determinado momento y puede ser posible además, que la Corte Constitucional haya declarado dicha norma constitucional por ese momento específico y en razón a determinadas circunstancias. Sin embargo, la norma sobrevive per se en el orden jurídico $y$, luego, unos años después, de manera descontextualizada, se la retoma y se la une a otra norma. Se trata de un proceso interminable de autoafirmación, de autoreproducción discursiva de la norma, sin ninguna referencia empírica consistente. Por las anteriores razones, el mecanismo de la emergencia no sirve en Colombia. Al contrario: lo excepcional se ha convertido en lo normal; el caso extremo, se ha convertido en el caso normal.

${ }^{8}$ Así expresa la idea Schmitt: "no existe ninguna norma que fuera aplicable al caos. El orden tiene que ser restablecido, de tal manera que el orden jurídico tenga un sentido". Ibídem, p. 19. En otro texto, sobre el Leviathan de Hobbes, dice, en relación con la decisión que le da vida en el orden jurídico a las normas: "Nada es aqui verdad, todo es aquí mandato". SCHMITT Carl, der Leviathan, Köln, 1982, p. 82. 


\section{El Derecho Penal de Enemigo}

Günther Jakobs, en un trabajo importante presentado al Seminario de Profesores de Derecho Penal alemán en el año de 1985, enfrenta las pretensiones legislativas eficientistas en ese país, que buscan criminalizar lo que se ha denominado como "estadio previo" a la lesión de un bien jurídico. Para Jakobs, la criminalización indiscriminada, que toca aún la esfera privada, expresa un derecho penal en el cual la tensión entre la protección de los bienes jurídicos tutelados y la libertad, se resuelve de manera radical a favor de la primera. La clásica definición de Franz von Liszt, acerca de cómo el derecho penal surge desde el primer momento en una situación de crisis -pues constituye aquel modelo de derecho que "busca la protección de bienes jurídicos, mediante la lesión de otros bienes jurídicos" - se resuelve a favor de la protección a ultranza de los bienes jurídicos. ${ }^{9}$

Sin embargo, según Jakobs, ello parte de un error esencial: considerar que la integración social real, sólo es posible a través de la intangibilidad de bienes jurídicos reales o supuestamente tutelados por el derecho penal. Cuando ello ocurre, según el autor, se trastorna la lógica de la reacción estatal penal frente al delincuente: éste es definido como tal, en la medida en que, como sujeto, pueda representar un peligro potencial para bienes jurídicos tutelados, de tal manera que el comienzo del peligro, así sea éste establecido bajo meras suposiciones, pueda en todo caso ser criminalizado.

La amenaza -sin duda una pieza clave dentro de la lógica eficientista- es la que autoriza una reacción penal en aquello que en el texto de Jakobs es trabajado como das Vorfeld-, es decir, el estadio previo a la comisión del delito. Es previo en relación con la realidad objetiva y, por ello, anterior a la conducta punible objetivada; pertenece por ello exclusivamente a la esfera de la subjetividad: se trata, ni más ni menos, que del fuero interno. También en Colombia tenemos desde luego este problema: la progresiva desestructuración dogmática de todo el sistema penal y la desestructuración de la racionalidad propia de los llamados "dispositivos amplificadores" - la tentativa o la coparticipación- del tipo penal, así lo demuestran. La criminalización del estadio previo no sólo representa un desorden en la noción de "iter criminis", sino que significa, ante todo, que "el autor viene definido tan sólo por el hecho de que puede constituir un peligro para el bien jurídico, con el añadido de que cabe anticipar, potencialmente sin límite alguno, el comienzo de tal peligro. El autor no tiene ninguna esfera privada, ningún ámbito para una conducta aún no relevante socialmente, sino que es concebido

\footnotetext{
${ }^{9}$ Liszt citado por BAURMANN, "Strafe im Rechtsstaat", en: BAURMANN Michael / KLIEMT Harmut (editores), Die moderne Gesellschaft im Rechtsstaat, Freiburg/München, 1990, p. 111.
} 
tan sólo como fuente de peligro o, en otras palabras, como enemigo del bien jurídico tutelado". ${ }^{10}$

El delincuente es convertido, en estas condiciones, en un enemigo. Es esa lógica de criminalización indiscriminada, aquella que produce, a su vez, un derecho penal de enemigo (das Feindstrafrecht). Contrario a la concepción del delincuente como un enemigo, concibe Jakobs al delincuente como un "ciudadano". A partir de esa definición, aquél -en tanto ciudadano- posee una esfera privada que no puede ser en ningún caso invadida. Al derecho penal de enemigo, se antepone así, un derecho penal del ciudadano (das bürgerliche Strafrecht). "Mientras el derecho penal de enemigo optimiza la mera protección de bienes jurídicos, el derecho penal del ciudadano optimiza la esfera de la libertad". ${ }^{11}$

Finalmente, en razón a la invasión del fuero interno, el enemigo es, para Jakobs y en la práctica, aquél que es juzgado haciendo abstracción de su esfera de derechos: en el ámbito sustantivo, es invadido en esferas no relevantes socialmente y negado en su condición de ciudadano; en lo procesal: es juzgado por fuera del ámbito de derechos y garantías propios del ciudadano. Es decir, por fuera del pacto social. Un derecho penal así es, como dice Winfried Hassemer, "anacrónico. Regresa al tiempo de una teoría de la filosofía del derecho penal y de la política criminal premoderna, según la cual el delincuente tan sólo era concebido como un violador de normas, como el 'extraño'. Ello es tan lejano a la filosofía de la ilustración, que muy al contrario ha sido la de concebir al hombre y a los derechos humanos, como los fundamentos del derecho penal y del derecho procesal penal y, con ello, la de situar el delincuente como parte del contrato social" ${ }^{12}$

10 JAKOBS Günther, "Kriminalisierung im Vorfeld einer Rechtsgutsverletzung", en: ZStW, 97, (1985), p. 753. A propósito de la exacerbación del valor de la amenaza como criterio exclusivo para la toma de decisiones políticocriminales, nos parece claro que una sociedad que no articule formas racionales de protección de valores que le sean fundantes, sino que recurra siempre a la función punitiva para ello, se halla equivocada de plano en el sentido mismo de esa protección. La confusión entre las esferas de las políticas públicas, de tal forma que la politica social sea en la práctica absorbida por la política criminal, y sustituida por ésta, tanto en el discurso como en la gestión social misma, dinamiza una perversión ya tradicional: la gestión se desarrolla a partir de una concepción según la cual sus destinatarios son siempre vistos como amenazas potenciales. Es la amenaza, y no el hecho de ser ellos sujetos de derechos, aquello que dinamiza la lógica de acción estatal frente a sujetos pertenecientes a sectores especialmente vulnerables. Este es uno de los aspectos centrales de un trabajo elaborado por el Profesor BARATTA Alessandro sobre los dilemas que afrontan las políticas públicas en países de alta conflictividad. BARATTA Alessandro, "Política Criminal : entre la política de seguridad y la política social en países con grandes conflictos sociales y políticos", en: Ciencias Jurídicas. Memorias, loc, cit., p. 68 y ss.

11 JAKOBS Günther, "Kriminalisierung im Vorfeld einer Rechtsgutsverletzung", en: ZStW, 97, (1985), loc, cit., p. 756.

12 HASSEMER Winfried, "Das Schicksal der Bürgerrechte im 'effizienten' Strafrecht", en: Strafverteidiger 7. (1990) 0. 329 Agreģo el autor además, que en un escenario social en el cual el delincuente es juzgado por fuera del pacto social, el derecho penal tiende a convertirse en la práctica "tan sólo en un derecho penal de enemigo". Ibídem, 329. Es de aclarar también, que el concepto de "derecho penal de enemigo" estudiado por Jakobs, es un concepto que ha ejercido un impacto muy importante sobre la discusión juridico-penal actual. Peter-Alexis 


\section{Carl Schmitt y la política como polemos: del derecho penal de enemigo en el caso colombiano}

El concepto general de derecho penal de enemigo desarrollado por Günther Jakobs, sufre en el caso colombiano una variación sustancial: en nuestro caso, el "enemigo" del derecho penal especial de la emergencia, surge de un contexto político, social y jurídico, en el cual la guerra, vivida como conflicto armado interno y generalizada en grandes porciones del territorio nacional, constituye una realidad. Por ello, si bien dicho "enemigo" es también concebido en Colombia en el marco de una respuesta particular estatal a fenómenos similares al caso alemán, como es el de la criminalidad organizada por ejemplo, en nuestro caso ésta, y de manera general toda aquella criminalidad afrontada por nuestra justicia penal de emergencia, conserva a su sombra el conflicto armado interno.

No se trata tan sólo entonces de una amenaza y un sujeto situado en uno de los polos de la tensión entre bien jurídico tutelado y bienes jurídicos restringidos por la respuesta penal, sino que esta respuesta tiene lugar en un escenario de violencia particular y específico del caso colombiano. Así mismo, en nuestro caso, el delincuente, desconocido como ciudadano -es decir, desconocido como portador de una "esfera intangible de derechos" - tiende en la práctica a ser tratado más como un objetivo de carácter militar : de ser un sindicado, pasa a ser un objetivo militar. Detrás de esta consecuencia grave, yace en gran medida la confusión existente entre la guerra y la política, el hecho indudable de haberse vivido entre nosotros la política sobre todo en

\footnotetext{
Albrecht por ejemplo, coincidiendo con la conclusión de Hassemer, concibe el desarrollo de "todo nuestro derecho penal hacia un derecho penal de enemigo-y hacia un derecho penal de peligro". ALBRECHT Peter-Alexis, "Das Strafrecht auf dem Weg vom liberalen Rechtsstaat zum sozialen Interventionsstaat", en: KritV, (1988), loc. cit. p. 201. Por su parte, Kindhäuser estudia las consecuencias que representa un derecho penal de enemigo, en relación con las posibilidades de fundamentación dogmática de los delitos de peligro, tanto abstractos como concretos. URS KINDHÄUSER, Gefährdung als Straftat, Frankfurt am Main, 1989, pp. 170-188. También en el caso italiano, esta noción ha tenido un amplio desarrollo. A manera de ejemplo, Luigi Ferrajoli se refiere a una peligrosa extensión del paradigma del enemigo. A su juicio, la conversión del " $\mathrm{L}$ ' imputato come nemico", no constituye un aspecto accidental de la legislación de emergencia, sino que le es esencial a ésta. FERRAJOLI Luigi, "L'imputato come nemico: un topos della giurisdizione dell' emergenza", en: Dei Delitti e delle Pene, 3. settembre-dicembre, (1983), pp. 581-594. Además, agrega Ferrajoli, en su trabajo más extenso sobre una teoría del garantismo penal, y que se cita aqui en la versión española: en virtud de la extensión del paradigma del enemigo, el sistema penal opera a través de "delitos de status" más que a través de "delitos de acción o de resultado", identificables, en vez de serlo mediante pruebas, "mediante valoraciones referidas a la subjetividad subversiva o sustancialmente antijurídica de su autor. De ello resulta un modelo de antijuridicidad sustancial, en vez de formal o convencional, que solicita investigaciones sobre los reos en vez de hacerlo sobre los delitos", y que actúa sobre la idea "de que se debe castigar no por lo que se ha hecho sino por lo que se es". FERRAJOLI Luigi, Derecho y Razón. Teoría del garantismo penal, Madrid, 1995, p. 821. Contrario a ello, afirma el autor que "la razón jurídica del estado de derecho, en efecto, no conoce enemigos y amigos, sino sólo culpables e inocentes. No admite excepción a las reglas más que como hecho extra o antijurídico, dado que las reglas -si se las toma en serio como reglas y no como simples técnicas- no pueden ser doblegadas cada vez que conviene. $Y$ en la jurisdicción el fin nunca justifica los medios, dado que los medios, es decir, las reglas y las formas, son las garantías de verdad y de libertad y como tales tienen valor para los momentos difíciles más que para los fáciles; en cambio, el fin no es ya el éxito a toda costa sobre el enemigo, sino la verdad procesal obtenida sólo por su medio..." Ibídem, p. 830.
} 
un sentido polémico $y$, por ello mismo, de haberse vivido a la sombra de confrontaciones armadas. En Colombia se ha vivido tradicionalmente la política como la confrontación irreductible entre enemigos. ${ }^{13}$

\section{7. ¿Quiénes son en realidad juzgados por la justicia penal de emergencia?}

Por lo anteriormente expuesto, las decisiones de política criminal son, en Colombia, decisiones sobre la enemistad. En el caso por ejemplo del "Estatuto para la defensa de la Justicia" que, como se recuerda, instituyó los jueces sin rostro en 1990, se mezcló todo tipo de actores que si bien han estado vinculados a la violencia política en Colombia, ellos se mueven en lógicas de acción completamente distintas. El gran narcoterrorista urbano era, en ese entonces, el enemigo absoluto. Él le había declarado una guerra al Estado. Contra ese actor específico pretendía responder el Estado a través de un endurecimiento radical de la justicia penal. Sin embargo, se asignó a este modelo de justicia penal especial el juzgamiento de actores que no eran los grandes terroristas. Se trata, por ejemplo, de actores que se mueven en una dinámica de protesta civil o de simples delincuentes comunes que son falsamente juzgados como terroristas en el contexto de un proceso penal sin respeto a las libertades y garantías fundamentales. Por eso, la primera pregunta que surgió en relación con este modelo de justicia penal especial, era respecto de quiénes irían a ser en la realidad juzgados por ella. ${ }^{14}$

La respuesta a esta pregunta ha sido clara en los 10 años de vigencia de la justicia sin rostro: no han sido los grandes terroristas los actores juzgados por ella. Si bien en muchos casos han sido grandes capos del narcotráfico, o miembros del crimen organizado, en la justicia sin rostro se han juzgado sobre todo actores que no pueden, en ningún caso, ser tratados como enemigos absolutos. En la investigación empírica más detallada sobre el funcionamiento de este modelo de justicia, adelantada por la Universidad Nacional, se encontró que "la población que es objeto de sindicación y juzgamiento de la justicia sin rostro, está lejos de corresponder a la descripción de peligrosos miembros de organizaciones criminales. En la mayor parte se trata de personas, autores o no de las conductas acusadas, que pertenecen a sectores desfavorecidos, con escasa educación, cuya subsistencia está limitada por agudas

\footnotetext{
${ }^{13}$ SCHMITT Carl, Der Begriff des Politischen. Text von 1932 mit einem Vorwort und drei Corollarien, Berlin, 1991. p. 25.

${ }^{14}$ El autor de este escrito alertó desde el principio sobre el grave problema que se abriría hacia el futuro en relación con quiénes irían a ser en realidad juzgados por la justicia sin rostro. Hoy, como se indicará aquí, se ha constatado, a través de investigaciones empiricas, que no han sido los grandes terroristas. Ver: APONTE Alejandro, $L_{a}$ "Constitución de 1991. La Administración de Justicia". Anélisis Polticy Engot2. (1021), in 4-59) APDNTE Alejandro. "Cómo matar a la Justicia en la tarea de defenderla: Estatuto para la defensa de la Justicia", en: Análisis Político, Bogotá, (1990), p. 78.
} 
precariedades económicas y sociales. En el Seguimiento de Expedientes realizado en los cinco lugares donde funciona esta justicia especial, con base en información consignada en la indagatoria, se encontró que las personas privadas de la libertad forman parte de la población económicamente activa, ya que el $85.8 \%$ está entre 18 y 40 años. Partiendo de la descripción de los oficios y actividades realizadas antes de ser privados de la libertad, se halló que la mayor parte eran campesinos (25\%), comerciantes o vendedores $(18 \%)$, obreros $(9.3 \%)$ y conductores $(7.4 \%)^{\prime \prime} .{ }^{15}$

En esa dirección, a juicio de un investigador, "la tipificación abierta y ambigua del delito de terrorismo ha contribuido a la 'criminalización' de sectores sociales y políticos ajenos al fenómeno terrorista". ${ }^{16} \mathrm{Al}$ mismo tiempo, se ha evaluado el impacto global que dicha legislación ejerce sobre el ámbito general de aplicación de la justicia penal : pese a que el sistema de jueces secretos "se ocupa de sólo aproximadamente el $7 \%$ de los delitos que conocen las autoridades, tiene a sus 'órdenes' el $43,8 \%$ del total de personas privadas de la libertad en Colombia". ${ }^{17}$

Éste es un hecho revelador: en Colombia, puede decirse sin lugar a dudas, que el proceso penal es en sí mismo la pena. Es un problema, además, de muchos códigos de procedimiento penal en América Latina, particularmente en su regulación de la figura de la detención preventiva. En virtud de esta figura, se tiene a una persona en la cárcel detenida de manera "provisional" por varios meses e incluso por años, mientras que el aparato de justicia, de alguna forma, le resuelve su situación jurídica. No se afecta la libertad como una medida extrema, sino que se detiene a alguien y en ese momento se comienza a investigarlo: la presunción de inocencia no opera en la práctica. ${ }^{18}$

\footnotetext{
${ }^{15}$ NEMOGÁ Gabriel Ricardo (director de la investigación), Justicia sin Rostro. Estudios sobre la Justicia Regional, facultad de derecho, Universidad Nacional de Colombia, Bogotá, 1996, p. 142 y S.

${ }^{16}$ PEÑA DÍAZ Héctor, Justicia Regional: apuntes para una reforma inaplazable. Evaluación, Bogotá, 1994, p. 51 y S. Con ello coincide la citada investigación de la Universidad Nacional: "Por los resultados obtenidos del seguimiento de expedientes se encuentra que no se trataría tampoco de personas vinculadas con actividades políticas o militares propias de la delincuencia organizada. De la información existente en los expedientes revisados, se establece que una mínima parte de las personas tenían actividades en cuerpos de seguridad o militares $(2.8 \%)$ y actividades politicas o guerrilleras $(3.3 \%)$, que la mitad de las personas apenas había alcanzado el nivel de educación primaria, y otro $27 \%$ el nivel de educación secundaria. El nivel de ingresos no pasaba de ciento cincuenta mil pesos para el $80 \%$ de las personas". NEMOGÁ Gabriel Ricardo (director de la investigación). Justicia sin Rostro. Estudios sobre la Justicia Regional, 1996, op. cit, p. 143.

${ }^{17}$ PEÑA DÍAZ Héctor, 1994, loc. cit., p. 51 y S.

${ }^{18}$ En el caso de los sindicados por delitos de especial gravedad, los términos para la detención preventiva constituyen el doble de los términos normales. Así, incluso muchas personas cumplen en la cárcel, detenidos "preventivamente", el mismo número de años de pena establecida para las conductas que se le han imputado y respecto de las cuales en ningún momento se les ha encontrado verdaderamente culpables. Se puede decir $\sin$ exagerar, que en Colombia se tiene preso a un sindicado, mientras que el aparato de justicia busca la forma de encontrar la prueba para condenarlo.
} 
Otra investigación, enmarcada dentro de la tarea de protección y defensa de los derechos humanos, halló que la justicia regional "criminaliza actividades legítimas de ciertos sectores de la sociedad", y que por ello, a su juicio, "sólo deberían ser juzgadas ante esta jurisdicción las personas que, para obtener decisiones judiciales favorables, presionaran mediante la violencia o amenazaran a los jueces o fiscales. Es este hecho real el que determinaría la 'peligrosidad' de los acusados y no la calificación genérica en la que se incluye, además de los 'capos' del narcotráfico y los altos dirigentes de la guerrilla, a sindicalistas, campesinos, comerciantes". ${ }^{19}$

Respecto de la criminalización de problemas eminentemente económicos, políticos o sociales, como es el caso, por ejemplo, de la criminalización de la actividad de la siembra de la hoja de coca en lugares muy apartados y abandonados, puede constatarse que ello ha traído consigo, como consecuencia paradójica, "su despenalización" ${ }^{20}$ Baratta, desarrollando esta idea, añade una referencia importante al problema de la selectividad en el sistema penal: "Entiendo por despenalización en este caso, el hecho de que un derecho penal eficientista, al aumentar el número de actos para penalizar, aumenta simultáneamente el número de eventos impunes, los cuales en un derecho penal normal representan un porcentaje altísimo de todos los eventos penalmente relevantes. Extendiendo desmesuradamente los programas de acción del sistema de justicia criminal, sin que pueda corresponder a ello un aumento adecuado de los recursos a disposición (lo cual llevaría a una especie de militarización de toda la sociedad) el eficientismo penal eleva los niveles de selectividad del sistema penal, al mismo tiempo que permanecen inalterables las variables tradicionales de la selectividad: también el derecho penal eficientista puebla las cárceles de sujetos débiles. En algunos países europeos que practican este modelo de derecho penal, más de la mitad de la población carcelaria está formada por tóxicodependientes y extranjeros no pertenecientes a la comunidad europea". ${ }^{21}$

${ }^{19}$ GÓMEZ Juan Gabriel y ZAMBRANO Sonia (editores). "Violaciones a las garantías procesales y los derechos fundamentales en la jurisdicción de orden público, hoy justicia sin rostro", en: Comisión colombiana de Juristas Bogotá, 1995, p. 50.

${ }^{20}$ BARATTA Alessandro, "Politica criminal. Entre la politica de seguridad y la política social en paises con grandes conflictos sociales y políticos", en: Ciencias Juridicas. Seminarios 9, Bogotá, (1998), loc, cit, p. 66.

${ }^{21}$ Ibídem, p. 66. Puede citarse en este contexto de reflexión el texto de René Girard, la violencia y lo sagrado, en el cual el autor reseña la capacidad que tiene la violencia- en este caso la violencia estatal- para "desplazarse" de un objeto a otro, en el marco general de la lógica sacrifical que le es inmanente al derecho penal. Ante una situación insoportable socialmente, como es la generada por la agresividad de una delincuencia incontrolada, la respuesta penal de emergencia se desplaza hacia una población distinta a la que origina dicha respuesta penal. O se desvía hacia aquella población, que si bien hace parte de una cadena criminal, es la más frágil dentro de dicha cadena. Es el caso por ejemplo de las llamadas "mulas" del narcotráfico. Estas son personas que transportan en su cuerpo la droga desde Colombia. Asi como las cárceles del mundo están llenas de estas personas, las cárceles de Colombia también lo están. La idea expuesta la expresa asi Girard: "La sociedad intenta desviar hacia una víctima relativamente indiferente, una victima 'sacrificable' una violencia que amenaza con herir a sus propios miembros, los que ella pretende proteger a cualquier precio". Luego, agrega el autor: "Al desviarse de manera duradera hacia la víctima sacrifical, la violencia pierde de vista el objeto apuntado inicialmente por ella. La sustitución sacrifical 


\section{Derecho penal de enemigo: hacia una dinámica del sacrificio}

Un utilitarismo eficientista, que busca justificar la generación de víctimas inocentes, cae en el enorme error de desconocer que cada víctima inocente que produce el derecho penal de enemigo, se debe "pagar" socialmente en el mismo contexto en el cual ella se ha originado: en el contexto de la violencia política y social generalizada. La tesis que se desarrolla en este escrito, es que las consecuencias que genera cada víctima del derecho penal de la emergencia, se van a manifestar como agudización de la violencia y del conflicto armado interno que son dinámicas que en principio se quieren controlar. Por esta razón, se asume aquí una crítica al utilitarismo. Dos autores de la tradición anglosajona pueden servir de referencia para dicha reflexión crítica. Rawls por ejemplo es claro: existen unos mínimos que en ningún caso pueden ser desconocidos a nombre del interés general o de las pretensiones de la mayoría. ${ }^{22}$ De la misma forma, Ronald Dworkin que, a partir de una teoría del derecho fundamentada en los derechos individuales se convierte en un agudo crítico del utilitarismo, establece que los derechos individuales y muy especialmente el derecho a una igual consideración y respeto- léase dignidad- son en esencia triunfos del individuo frente a las mayorías. ${ }^{23}$

\section{Función de policía y derecho penal eficientista de enemigo}

Una de las consecuencias más graves en la práctica del modelo eficientista de derecho penal, tiene lugar en relación con la función de policía. De hecho, una de las columnas vertebrales de la justicia sin rostro, ha sido la concesión de grandes poderes a las organismos de policía y a los organismos de seguridad del Estado. A nuestro juicio y ello puede ser una característica de la mayor parte de los sistemas penales del mundo, aunque en el caso colombiano el fenómeno es más agudo, el proceso penal se juega en la práctica cotidiana en la actuación de los organismos de policía. El destino del proceso se juega en la manera cómo los organismos de seguridad recogen y administran la prueba judicial.

Ello adquiere en Colombia, además, una especial complejidad, pues en este país existe un enorme grado de fragmentación territorial: el Estado no tiene una presencia efectiva en grandes porciones del territorio nacional que han sido ocupadas por actores

supone una cierta ignorancia. Mientras permanece en vigor, el sacrificio no puede hacer patente el desplazamiento sobre el que está basado". GIRARD René, La violencia y lo sagrado, Barcelona, 1995, p. 12 y S.

22 Así lo expresa el autor: "Each person possesses an inviolability founded on justice that even the welfare of society as a whole cannot override. For this reason justice denies that the loss of freedom for some is made right by a greater good shared by others. It does not allow that the sacrifices imposed an a few are outweighed by the larger sum of advantages enjoyed by many". RAWLS John. Theory of Justice, 1971, p, 3 y S.

${ }^{23}$ Asi lo expresa Dworkin: "The institution of rigths is therefore crucial, because it represents the majority's promise to the minorities that their dignity and equality will be respected. When the divisions among the groups are most violent, then this gesture, if law is to work, must be more sincere". DWORKIN, Rights Seriously (1978), p. 205. 
colectivos como las guerrillas, los grupos de autodefensa, los grupos paramilitares, etc. Ello ha hecho que en el territorio colombiano se viva una especie de neo-feudalismo. En Europa, tal como lo ha sintetizado lúcidamente Carl Schmitt, el Estado se encuentra constituido por un afuera y un adentro, de tal manera, que en el afuera permanezca la posibilidad de la guerra y por ello actúe el ejército, en el adentro actúe la policía, la administración y se halle asegurada la paz. En Colombia, al contrario, dentro del mismo territorio se mezclan varios adentros y varios afueras, a la manera feudal: los actores colectivos violentos cierran las fronteras entre sí y las defienden con sus propios ejércitos. En muchos lugares, el Estado es apenas un actor más que compite por el control territorial. Dentro de las múltiples consecuencias que se producen por esta confusión, se genera el hecho de que muchas veces el ejército ejerce funciones de policía: estas funciones se entremezclan y se confunden. De hecho, muchos organismos que aparentemente ejercen funciones de policía, como por ejemplo, escuadrones especiales contra el narcotráfico, en realidad ejercen funciones propias del ejército.

Se trata de un escenario de confusión agravado además por las mismas normas. Para citar un ejemplo, en 1990 se le dio la posibilidad a las fuerzas armadas para que ejercieran funciones de policía judicial. Es decir, los organismos militares podían recoger y presentar pruebas dentro de un proceso penal. Ello representa en la práctica una militarización de la policía judicial. Esto significa, al mismo tiempo, que el escenario de la confrontación se continúa directamente en el escenario de la administración de justicia. Cuando uno de los actores, directamente involucrados en el conflicto armado, tiene la posibilidad de recoger las pruebas, se quiebra el principio de la neutralidad estatal. Su capacidad directa para reconstruir el escenario del conflicto, hace que el Estado pierda consistencia como tercero neutral. Más bien, el enfrentamiento bélico se continúa en el proceso penal. A pesar de que la Corte Constitucional, en la revisión de esta norma, trató de mermar sus efectos, ésta y otras normas, hacen posible concluir que el derecho penal de emergencia en Colombia, como derecho penal de enemigo, representa la "continuación de la guerra por medios civiles". ${ }^{24}$

\section{Sobre la desinstitucionalización de la función punitiva}

Esta conclusión, que se dirige sin duda a la esencia del derecho penal de emergencia en Colombia, hizo que en el contexto de una entrevista personal con el director del Instituto Max-Plank en Freiburg, Prof. Albin Eser, éste pensara que en

\footnotetext{
${ }^{24}$ Esta expresión afortunada se la debo al profesor Jörg Arnold, como fruto de una intensa conversación sobre el derecho penal de enemigo, tanto en el caso de Alemania como en el de Colombia, en el marco de una invitación ofrecida por el Instituto Max-Planck para Derecho Penal Extranjero e Internacional de la ciudad de Friburgo (Br.). Alemania, en el otoño de 1997.
} 
ningún caso el derecho penal de enemigo en Colombia podía concebirse válidamente como derecho ${ }^{25}$ Esta afirmación, inquietante en extremo, le da actualidad, como en la Alemania actual en relación con la manera de juzgar a militares de la antigua Alemania del Este que ordenaron fusilar a quienes pretendieron pasar el muro de Berlín, a la conocida fórmula de Gustav Radbruch sobre la arbitrariedad legal vs derecho justo supra-legal. Sin embargo, aplicarla en el caso colombiano, es un error metodológico y oculta en todo caso la realidad de que el derecho penal de la emergencia tiene una existencia concreta, produce sentencias de todo tipo, mantiene en las cárceles a un número muy elevado de personas, se levanta sobre una infraestructura muy costosa, y viene funcionando desde hace varias décadas.

Pero tampoco esta constatación quiere decir que este modelo especial de derecho penal no tenga enormes inconsistencias dogmáticas y de todo tipo. Se trata, sin duda, de un modelo al cual le falta una mínima racionalidad que lo pueda justificar válidamente como derecho. En él han primado, en todo caso, las decisiones de política criminal. Franz Von Liszt advirtió lúcidamente que el derecho penal constituye la barrera infranqueable de la política criminal. ${ }^{26}$ En esta frase se resume una pregunta central en relación con cualquier posibilidad de legitimación real que se pueda dar socialmente al derecho penal. En el caso colombiano, como se ha dicho, las decisiones de política criminal han prevalecido sobre el derecho penal y su racionalidad interna. Además, la política criminal se ha vivido muchas veces como política a "secas" y, a su vez, la política ha sido instrumentalizada en función del conflicto interno. En estas condiciones, los niveles de legitimidad del derecho penal son desde luego muy precarios.

Un derecho penal funcionalizado en relación con intereses coyunturales de la guerra y la política, es un derecho penal que lleva en sí el peligro permanente de desinstitucionalizarse. Es decir, desde las normas mismas, un derecho penal así corre el peligro de ser simplemente una respuesta radical de facto. En estas circunstancias y retomando la consideración de Albin Eser, es importante traer aquí una conclusión de Luigi Ferrajoli cuando evalúa la legislación penal de emergencia en Italia. Según el autor, si se considera como cierto que "nuestro país había entrado en guerra con los terroristas, entonces las prácticas de la emergencia han sido políticamente legítimas, pero no se ha tratado ya de derecho penal, sino de mero ejercicio de la fuerza con fines defensivos". ${ }^{27}$ En este caso, prosigue el autor, "se debe hablar de no derecho, es decir,

\footnotetext{
${ }^{25}$ Entrevista personal con Albin Eser, en el otoño de 1997.

26 "Das Strafrecht ist die unüberstreigbare Schranke der Kriminalpolitik", Franz von LISZT, en: Liszt, Aufsätze und Voträge, Berlin, 1905, p. 80.

${ }^{27}$ FERRAJOLI Luigi, Derecho y Razón. Teoría del garantismo penal, Madrid, 1995, op. cit, p. 830.
} 
de defensa de hecho, justificada entonces por la necesidad y hoy injustificada al haber terminado el terrorismo" ${ }^{28}$

\section{Colombia: entre el siglo XVII y el siglo XXI}

Esta conclusión sirve sin duda para el caso colombiano en relación con decisiones que se deben tomar con toda sinceridad: si se concluye que en este país no existe ninguna posibilidad distinta de luchar contra el crimen, que no sea a través de políticas criminales totalitarias o de una expansión incontrolada del derecho penal, ello debe decirse claramente. Si se concluye que el crimen en este país es tan grande que no es posible afrontarlo respetando los derechos y las garantías, ello debe decirse sin mentir. De hecho, la criminalidad en Colombia es una de las más altas, per capita, del mundo. Pero lo que no puede hacerse es implementar un derecho penal que se sabe de antemano que no se encuentra basado en los principios constitucionales y decir sin embargo, que sí lo está, sólo porque hay una Constitución Política que así lo obliga. No se puede continuar mostrando un modelo particular de derecho penal que niega la Constitución, como si éste la respetara. Se trata de una decisión política que debe tomarse $\mathrm{y}$ deben asumirse sus consecuencias.

Toda actitud no sincera genera nuevas decepciones. Siguiendo por ejemplo a Niklas Luhmann, es fácil entender que las expectativas sociales no cumplidas, a través de un derecho penal que ni siquiera posee un efecto simbólico, agravan aún más los problemas que supuestamente se pretenden combatir con el derecho penal. Una de las características del eficientismo penal es que éste presupone una forma de legislar completamente irracional, a partir de la cual, una norma se refiere a otra norma anterior y ésta a su vez se remite a otra y así sucesivamente, mientras que los problemas no se resuelven. Con la expresión More of the same se puede caracterizar muy bien el eficientismo penal. En este sentido y también reflexionando con Luhmann, tiene razón un autor ya citado, al afirmar que "observado desde la óptica sistémica, el eficientismo penal es un ejemplo clásico del círculo vicioso de la respuesta a una desilusión debida a la percepción de la ineficacia de la reacción penal frente a determinados problemas. El eficientismo, podemos decirlo con la terminología de Luhmann, no responde cognitivamente, sino normativamente a la desilusión. Se resiste a aprender, y en cambio de buscar otras reacciones más eficaces, busca extraer más eficacia de la respuesta penal, aumentando la intensidad del derecho penal, en contra

${ }^{28}$ Ibidem, p, 830 . 
del principio de legalidad y de la Constitución, y en contra del buen funcionamiento y la legitimación de la administración de justicia penal" ${ }^{29}$

Ahora bien, al contrario de algunos partidarios del eficientismo a ultranza, el autor de este escrito piensa que sí es posible instaurar en Colombia un derecho penal del ciudadano, en tanto derecho penal de la Constitución. Como en todos los demás ámbitos de la vida pública, este país debe vivir también simultáneamente, en su derecho penal, varios siglos: debe afrontar los dilemas del siglo XXI como es el problema de la ecología, de la clonación biológica, de las exigencias del internet, de los medios de comunicación, etc. Pero es un país, que al mismo tiempo, debe afrontar procesos de construcción de Estado propios de los siglos XVI y XVII europeos. Se vive simultáneamente en varios siglos de historia. Desde el punto de vista constitucional, se ha tenido que instaurar un Estado social de derecho, sin haberse vivido verdaderamente el Estado de derecho. Desde el punto de vista del derecho penal, se quieren imponer las modas funcionalistas y post-modernistas de algunos países europeos, en un país que no ha vivido todavía ni siquiera la experiencia de la modernidad. Al contrario, creemos que en Colombia se trata de vivir la experiencia del derecho penal liberal clásico, enriquecido desde luego con aportes dogmáticos hoy inevitables, pero levantado sobre el respeto a unos mínimos que significan, ni más ni menos, una contribución efectiva a la paz.

\section{El derecho penal: entre los costos de la paz y la fatalidad de la guerra}

Para Hobbes, la paz es una condición empírica indispensable para la existencia del Estado. En Colombia, esta condición no se cumple. Ello ha enfrentado dos modelos de derecho penal: uno, basado en una política de pacificación eficientista, a partir de la cual los derechos y las garantías son concebidas como obstáculos para el derecho penal. El otro modelo reconoce que si bien la paz es una condición fundamental para la existencia del Estado hoy, especialmente por el desarrollo de la teoría de los derechos fundamentales, no es ésta la única condición y, por ello, el ejercicio de la función punitiva debe adelantarse de acuerdo con una política integral de respecto a los derechos fundamentales. Es esta la conclusión que compartimos con Baratta cuando, en su trabajo escrito en función de países de alta conflictividad, antepone la "eficiencia del pacto social", al desnudo eficientismo penal. ${ }^{30}$

Esto implica una revaloración de la noción misma de pacto social. En éste se deben incluir aquellos sectores tradicionalmente olvidados dentro del mismo. Por ello,

\footnotetext{
${ }^{29}$ BARATTA Alessandro, "Política criminal. Entre la política de seguridad y la política social en paises con grandes conflictos sociales y políticos", en: Ciencias Jurídicas. Seminarios 9. (1998), loc, cit., p.64.

${ }^{30}$ Ibídem, p. 59 y ss.
} 
puede concebirse que las otras condiciones distintas de la paz como condición empírica y necesaria para el pacto social, residen en la eficacia de las normas que regulan la organización y la división de los poderes del Estado y los derechos fundamentales de los ciudadanos. De esta forma, la construcción de un derecho penal normal, diferente a un modelo de derecho penal de emergencia, pasa "por una interpretación y realización dinámica de las Constituciones de los estados sociales de derecho, por una política global de desarrollo social y de protección integral de los derechos civiles, sociales, económicos, culturales y de participación política, tal como lo establecen dichas Constituciones" 31

En estas circunstancias, el papel del derecho penal se hace mínimo, porque de las demandas generalizadas de justicia se deben encargar múltiples instancias sociales y no el derecho penal como un instrumento privilegiado para ello. De las demandas de justicia material y de efectividad de los derechos fundamentales, se deben encargar las instancias para ellos encargadas: no existen fines promocionales en el derecho penal. Su papel es exclusivamente la protección de bienes jurídicos esenciales para la convivencia social. De esta forma, el derecho penal normal no es otro que el derecho penal de los Estados sociales de derecho, es decir, el derecho penal mínimo, entendido como la parte residual de la política penal que queda dentro de una política integral de protección de los derechos.

\section{A manera de conclusión: hacia un derecho penal de la Constitución}

Un derecho penal mínimo, como derecho penal del ciudadano, que constituye el derecho penal de la Constitución, representa una gran contribución al propósito de paz que se busca por las grandes mayorías en Colombia. Al contrario, una pacificación eficientista, basada en un uso privilegiado de políticas represivas, generará falsas expectativas sociales de solución de conflictos y sus fracasos los pagará en el contexto de la violencia generalizada. Se trata, sin embargo, como en todas las cosas importantes de la vida, de una apuesta.

Precisamente en función de esta apuesta por un derecho penal más democrático, en mayo de 2000 la Corte Constitucional de Colombia declaró inconstitucional múltiples normas que hacían parte de la Ley 504 de 1999, o denominada "Justicia especializada contra el crimen organizado". Los antecedentes de esta ley se encuentran en la Ley estatutaria de la administración de justicia de 1996. En ese año, a través de la ley que organizó la administración de justicia, se estableció que la justicia sin rostro, basada en la reserva de identidad de jueces, fiscales y testigos, debía desaparecer en el mes de junio de 1999.

31 Ibídem, p, 62 
La ley ordenó, además, que el Congreso de la República impulsara investigaciones de carácter empírico sobre el funcionamiento, en cerca de 10 de años, de la justicia sin rostro. Las investigaciones no se llevaron a cabo, la discusión parlamentaria se improvisó -como en la mayoría de los casos- y se expidió la ley 540 de 1999. Se había establecido que se tratara de una ley transitoria, para que se fuera desmontando en la práctica la justicia secreta. Sin embargo, a esta ley se le dio una vigencia hasta por 8 años. Esa es la trampa de lo excepcional en Colombia: se expide una norma con un supuesto carácter transitorio, y se le dan 8 años de vigencia. Como ya se ha dicho antes: ¿Cómo puede ser una ley transitoria con 8 años de vigencia?

El segundo grave problema de la ley es que conservaba la figura de los fiscales, jueces y testigos sin rostro. En el momento de ser expedida, diversos miembros de la comunidad jurídica nacional se preguntaban: ¿Pero cuál es el tránsito hacia una justicia normalizada, si se conserva, con otro nombre, la justicia sin rostro basada en la reserva de identidad? De nuevo se caía en lo mismo: Colombia se mostraba incapaz de establecer un derecho penal normalizado. Sin embargo, varios ciudadanos demandaron la ley ante la Corte Constitucional a través de la llamada "acción pública de inconstitucionalidad". El magistrado ponente inicial quiso declarar inconstitucional toda la Ley que consta de 53 artículos. Pero fue derrotado. Al final, otro magistrado redactó una sentencia que declaró inconstitucional varios de los artículos de la Ley 504 de 1999. Existió, de manera general, una posición en contra de la ley especial de emergencia contra el crimen organizado. Lo más importante que hizo la Corte, fue que declaró contra la Constitución la reserva de identidad de funcionarios y testigos. ${ }^{32}$ Es decir, eliminó formalmente la justicia sin rostro.

Con esta decisión se da un paso adelante. Más allá de todas las críticas que puedan hacerse a cierta ambigüedad de la Corte Constitucional, como en muchas oportunidades, los jueces, en el caso colombiano, han establecido unos mínimos democráticos para el derecho penal. Sin embargo, la realidad es que existe una Ley que establece un régimen excepcional, aunque ella contiene figuras menos drásticas a las que son habituales en este país. Esto quiere decir, que la tarea por construir un derecho penal del ciudadano, sigue abierta y las discusiones sobre eficiencia en el sistema judicial, sobre cómo afrontar el crimen organizado y el terrorismo, sobre cómo diferenciar entre los más distintos actores de la guerra, y de diferenciar aquellos actores que se mueven en una "zona gris" y que están desarmados, conservan toda su actualidad y validez. Por esa razón, es en la perspectiva de la paz que hay que pensar nuestro derecho penal. Precisamente, como se dijo desde el principio, el derecho penal en Colombia hay que comprenderlo en el contexto general de las relaciones entre

\footnotetext{
${ }^{32}$ Corte Constitucional, sentencia No. C-329 de mayo de 2000. Bogotá, pp. 45 y ss.
} 
conflicto y derecho. Pero, se repite de nuevo, se trata, al fin y al cabo, de una difícil apuesta. 